students, in order to qualify for the M.D. degree, in 26 out of the 156 institutions in the United States was 'over 4,000 hours.' ${ }^{*}$ Inasmuch as the minimum requirement established by the Association of American Medical Colleges in June, 1899, was 'at least 3,300 hours,' it can be assumed that the 26 colleges mentioned above include the institutions of highest standing.

A laboratory course of physics of 36 hours, such as the one given at Columbia University, represents less than one per cent. of the total work required on the 4,000 hour basis.

Physical Laboratory,

\section{C. Trowbridge.}

Columbia University, N. Y.

\section{SOME PRELIMINARY EXPERIMENTS ON THE MOTION OF IONS IN A VARYING MAGNETIC FIELD.}

THE experiments described below were suggested by the negative results of $\mathrm{V}$. Crémieu's search for a force acting on a static charge in a varying magnetic field. $\dagger$ The scheme of the Crémieu experiment may be briefly described by the statement that a disc which was charged to a high potential was suspended in the field of a strongly excited electromagnet. Upon breaking the current the disc should have experienced a force in accordance with the Maxwell equation

$$
\operatorname{Curl} E=-\frac{1}{E} \frac{\partial H}{\partial t} .
$$

The quantity of electricity that can be placed on a body of considerable dimensions is comparatively small, so that in the case of the Crémieu experiment $e / m$ was a small quantity.

It occurred to me to use the negatively charged ions in an ionized gas as the car-

* 'Education in the United States,' N. M. Butler.

$\dagger$ Cremieu, Annales de Chemie et Physique, ith Series, I., 24. riers of the static charge; in the case of ions $e / m$ is very large, being about $4 \times 10^{17}$ E.S. An ion, because of its high charge, should move with considerable velocity in a varying field of moderate strength. For the purpose of showing the theoretical magnitude of such ionic motion in such a field I will assume an ideal case. Suppose that a cylindrical vessel is placed in a coil of a few turns through which is passing an oscillatory current of high frequency. Assume that there is a complete vacuum except for one negative ion which at the initial time is at rest at a distance $r$ from the center of the coil. The ion will be acted upon by a force the direction of which will be a circle of radius $r$ about the magnetic center of the coil. Neglecting the centrifugal acceleration and the change in apparent mass due to its motion, if the maximum strength of the field at the position of the ion is 100 C.G.S. and the frequency is $10^{6}$, it may be shown that the ion would execute a harmonic oscillatory motion in a circular path around the center, with a maximum displacement from the position of rest of $20 \mathrm{~cm}$. and a maximum velocity of $13 \times 10^{7} \mathrm{~cm}$. per second.

Since for the purpose of experiment, it is desirable to have ions in abundance and a rapidly varying magnetic field, I have made use of the well-known electrodeless discharge in the Tesla oscillatory field, as in this form of discharge the gas is highly ionized and the, field is of high frequency. In the actual phenomena the amplitude is of course many times smaller than that calculated above. The ions probably moye but a short distance and are then stopped by collisions with the molecules, producing by the collision many other ions which by impact produce yet others and thus the effect accumulates until a strong current, the ring discharge, is produced.

To demonstrate by experiment that some such motion actually exists I have made 
use of a miniature anemometer similar to those I have used to show the oscillatory motion of the air in a stationary sound wave.*

The anemometer possesses the convenient property of rotating in one direction, whatever may be the direction of the particles acting upon it, so that an oscillatory motion of the ions should produce rotation provided their amplitudes of oscillation are at least as great as the radius of the cups.

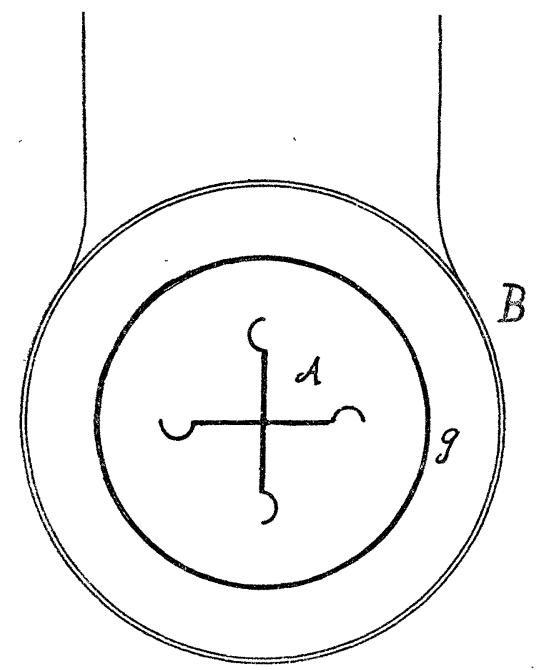

The arrangement of the apparatus was as follows: Four large twenty-liter Leyden jars were joined two in parallel, the inner coatings of each pair being connected with the spark gap and the outer coatings with the coil $B$. Within this coil, which consisted of eighteen turns of coarse wire, was placed a cylindrical glass vessel $\mathrm{g}, 5 \frac{1}{2} \mathrm{~cm}$. in diameter. The vessel was in permanent connection with a mercury air pump. A miniature anemometer $A$, consisting entirely of glass, was mounted on a needle point so as to turn with great freedom. The anemometer was $3 \frac{1}{2} \mathrm{~cm}$. in diameter and the cups, which were half cylinders, were each $2 \mathrm{~cm}$. long and $6 \mathrm{~mm}$. in diameter. Between the coil and the vessel was

* Amer. Jour. Sc., February, 1902. placed a Faraday cage, which was made by attaching narrow strips of tin-foil on a glass cylinder so that the strips were perpendicular to the plane of the coil. This was found to shield the vessel very well from external electrostatic effects. The jars were charged by a large induction coil excited by an alternating current of torty complete periods per second. The length of the spark gap was $11 \mathrm{~mm}$. When the proper degree of exhaustion was obtained, upon the passage of the sparks, the white ring discharge was produced and the anemometer rotated in the direction of the convex side of the cups.

The experiments are given below: Forward rotation signifies rotation in the direction of the convex side of the cups.

1. Pressure $3.6 \mathrm{~cm}$. mercury. A faint red light in vessel. Anemometer does not rotate. Vessel cool.

2. Pressure $1.1 \mathrm{~mm}$. The red light deeper and stronger. The anemometer does not rotate. Vessel cool.

3. Pressure $.64 \mathrm{~mm}$. The white ring discharge is obtained. Anemometer rotates forward about two revolutions per second. The vessel becomes very hot.

4. Pressure $.17 \mathrm{~mm}$. The anemometer rotates forward but not so rapidly as in experiment 3 . After the interruption of the Tesla current the anemometer rotates backward. If the current is kept on for some time, especially when the vessel is wrapped closely in paper to confine the heat, the walls of the vessel become nearly as hot as the vanes of the anemometer and the anemometer rotates but very little backward.

5. Pressure $.058 \mathrm{~mm}$. Immediately on the appearance of the white electrodeless discharge the anemometer rotated backward. Upon wrapping the vessel with felt or paper to confine the heat the following is observed: When the current is turned on the anemometer rotates at first back- 
ward; after a short time it turns more slowly, stops, and then rotates forward. This can be continued but a short time as the temperature becomes so high as to endanger the anemometer.

6. Pressure $.024 \mathrm{~mm}$. . The anemometer rotated backward, but when the vessel was wrapped with a non-conductor of heat it rotated forward as in experiment 5 .

7. Pressure $.0017 \mathrm{~mm}$. The electrodeless discharge was not obtained and the anemometer did not rotate. Vessel remained cool.

8. In the experiments 1 to 7 the distance from the outer edge of the anemometer cups to the walls of the vessel was about $1 \mathrm{~cm}$. Another vessel was used also in which the cups were much nearer the walls. With this the backward rotation was much stronger in all cases. The pressure at which the backward rotation was first obtained was much higher than in experiments 4 to 7 .

9. In this experiment the vessel contained a small mill which was similar in construction to the anemometer, excepting it had flat vanes. This did not rotate at any degree of exhaustion in the strongest discharge that could be obtained.

10. A much larger vessel was used for this experiment. It was $12 \mathrm{~cm}$. in diameter and the anemometer was but $3 \mathrm{~cm}$. in diameter, so that the distance between the walls and the cups was $4 \frac{1}{2} \mathrm{~cm}$. The rate of rotation was surprisingly great, attaining a velocity of forty revolutions per second. At no degree of exhaustion did the anemometer rotate backward. This indicates that at this great distance $\left(4 \frac{1}{2} \mathrm{~cm}\right.$.) between the walls and the cups there is no radiometer effect. It is perhaps desirable also to mention that a vessel was constructed having two anemometers, one above the other, mounted with the convex sides turned in opposite directions. At the proper degree of exhaustion these ro- tated in opposite directions, each turning in the direction of the convex side of its cups.

The backward rotation appears to be due to the heat interchange between the convex side of the cups and the walls of the vessel, because: (1) By experiment 4, the anemometer is acted on by a force driving it backward, which persists for some time after the current is interrupted. This force is much less when the cups and the vessels reach nearly the same temperature. By experiments 5 and 6 , the backward rotation is only obtained when there is heat interchange between the cups and the walls. The effect of wrapping the vessel with a non-conductor of heat is to make the inner surface of the walls nearly as hot as the cups of the anemometer. When this condition is obtained, the backward force nearly disappears and the forward force due to ionic motion predominates.

This backward force appears to be a true radiometer effect since it increases as the vacuum becomes higher. In experiments 3 and 4 the distance from the cups to the walls is probably greater than the mean free path of the molecules and the radiometer effect is small. In experiment 8 the radiometer effect is stronger and appears at a higher pressure as the cups are nearer the walls and the mean free molecular path necessary for a radiometer effect is shorter.

We may regard the molecule from which the negative ion has been separated as a carrier of a positive charge, and so it also will be acted upon by the varying magnetic field. Its velocity and amplitude will be much less than that of the negative ion. The amplitudes will be inversely proportional to the square roots of their masses, since the energy is the same in both cases. If their amplitudes are of the same order of magnitude as the radius of the cups, the positive ions will act on the anemometer also. 
There are thus two opposing forces acting on the anemometer, the one due to the motion of the ions and the other due to the transfer of heat from the centers outward. The direction of rotation depends upon which of these forces is in excess. No attempt has yet been made at quantitative measurements, although such measurements could probably be made by a torsional suspension of the anemometer in a vessel as large as that described in experi, ment 10 .

It is my hope in the near future to investigate a possible difference of potential between the walls and the center of the vessel, and also to study the motion of the cathode rays in a Tesla field.

In addition to furnishing direct support to the Maxwell equation, the experiments may be of some value from their bearing on the electron theory of electricity. The electrodeless discharge consists of a rapidly alternating current of electricity similar to that which would be produced in a metal ring placed within the coil. It thus appears that such current is at least accompanied by ionic motion even if such motion does not constitute the current itself.

Götringen, February 17, 1902.

Bergen Davis.

\section{THE TROPICAL LABORATORY AT MIAMI, FLORIDA.*}

THE extent to which the government of the United States is making provision for scientific investigation in connection with the work of its various departments, notably that of the Bureau of Plant Industry, is a matter of congratulation. To scientific workers especially, it is a gratifying fact that the laboratories established primarily for the study of plant diseases and other subjects of a practical nature are being thrown open to investigators of widely dif-

\footnotetext{
* Read before the Michigan Academy of Science, March 27, 1902.
}

ferent aims, their facilities being freely placed at the disposal of students engaged in any line of research whatever. One of these, the . Tropical Laboratory of the United States Department of Agriculture, has been established so recently and offers such exceptional advantages that its location and facilities should be widely known. This laboratory, located at Miami, Fla., in 1899, was formally established under its present name in 1902. After the discouraging failure of much of the experimental work at Eustis, Fla., occasioned by the disastrous freezes of 1894-95, it became apparent that another place must be selected less subject to climatic vicissitudes, and thus far there is every reason to believe that the location now chosen will admirably fulfil the requirements for such a station.

Miami is situated a little south of the twenty-sixth parallel of latitude, in direct communication with the north by rail, and with Nassau, Havana, and Key West by the Peninsular and Occidental Steamship Line. The city, only a few miles from the Everglades, is healthfully built on the coral breccia which forms the underlying rock, and looks out on Biscayne Bay, landlocked by the northeastern extension of the Florida Keys. Its delightful climate, permitting all sorts of outdoor study and exploration in midwinter, is not the least of its many advantages. The laboratory, situated a mile south of town, is easily reached in ten minutes by wheel over a smooth rock road. Six acres of land belong to the station, upon which experiments in acclimatization and plant breeding are in progress. The laboratory building is a p]ain but substantial and well-arranged structure, with office and library in which are shelved upwards of two thousand volumes, including pamphlets and periodicals, among which are the Botanisches Centralblatt, Botanischer Jahresbericht, SCIENCE, the Botanical Gazette and other current 